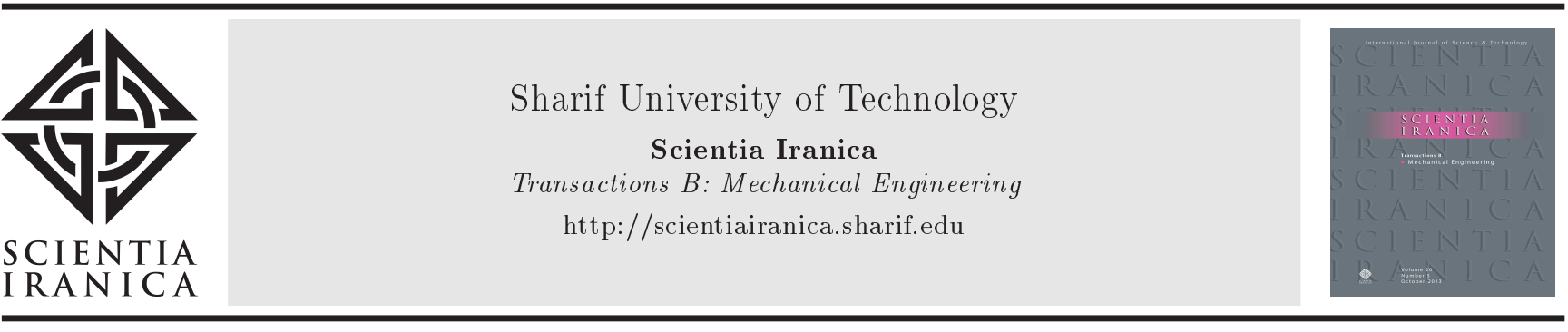

\title{
Impact of nonlinearity on bolt forces in multi-bolted joints: A case of the assembly stage
}

\author{
R. Grzejda* \\ Faculty of Mechanical Engineering and Mechatronics, West Pomeranian University of Technology, Szczecin, Poland.
}

Received 10 October 2016; received in revised form 15 July 2017; accepted 16 April 2018

\section{KEYWORDS}

Multi-bolted joint;

Nonlinearity;

FE-modeling;

Assembly stage;

Preload.

\begin{abstract}
This study concerns modeling, computation, and analysis of multi-bolted joints in the assembly stage. The physical joint model is introduced as the assembly of the following three basic subsystems: a set of fasteners (bolts), a flexible joined flange, and a contact layer between it and a rigid support. The Finite Element Method (FEM) was used for modeling. Bolts were replaced by the bolt models of the spider type. The joined flange was modeled with spatial finite elements. As a model of the contact layer, the Winkler contact layer model was adopted. The truth of the theorem was tested, according to which nonlinear characteristics of the contact layer might have an insignificant impact on the final computational values of bolt preloads in the case of sequential tightening of the joint. The results of the calculations for the selected multi-bolted joint are given and compared with the experimental results. Conclusions of paramount importance to the engineering practice are comprised.

(C) 2019 Sharif University of Technology. All rights reserved.
\end{abstract}

\section{Introduction}

Multi-bolted joints are made up of many bodies being in a contact [1-3]. For this reason, they are most often referred to as nonlinear systems in modeling and calculations. The origin of this nonlinearity lies in the surface texture of the joining elements, which after mechanical processing are characterised by roughness [4,5]. In fact, joining a pair of elements with rough surfaces is related to the nonlinearity of mechanical properties of the created contact joint.

However, the connection of two elements joined in a multi-bolted system is a special case of the contact joint. It can be assumed that the multi-bolted joint in the assembly stage is loaded only with normal forces derived from the preload of bolts. Taking

\footnotetext{
*. Tel.: +48914494969; Fax: +48914494564
}

E-mail address: rafal.grzejda@zut.edu.pl

doi: $10.24200 /$ sci. 2018.20320 into account contact phenomena between the joined elements in this case, it is sufficient to consider only normal characteristics of the contact joint (for a review, see [6]). Such characteristics can be represented with good approximation through exponential functions [79]. Progressive tightening of the bolts in the pretensioning process [10-12] is equivalent to gradual tightening of the contact layer located between the joined elements. In such a process, roughness of the surface texture of the elements has less and less influence on mechanical properties of the contact joint. Therefore, it can be assumed that typically nonlinear characteristics of the normal deformation may be replaced by linearised counterparts. This theorem is established in the present study, which contains a continuation of the theme of modeling multi-bolted joints in the assembly stage inaugurated in the previous paper [13].

Complex multi-bolted joints are most often modeled and calculated using the finite element method. For modeling of the joined elements in such connections, spatial finite elements are usually used. In 
contrast, the bolts are replaced with various types of models. The most accurate types of these models are the 3D models of the bolts. At the same time, however, they are the most time consuming models in calculations. 3D modeling strategies can be summarised in the following order:

- Use of a uniform component model linking together the bolt head, the bolt shank, and the nut [14-17];

- Use of a model consisting of the bolt head and the shank without the tread $[18,19]$;

- Use of a full model consisting of the bolt head, the bolt shank, and the nut including the tread [20].

Sometimes there is no need to build complex bolt models. This occurs, for example, when determining the bolt preload during tightening the multi-bolted joint. It is therefore reasonable to look for simplified models. In practice, in addition to spatial models of the bolts, the following substitute bolt models are used:

- Spring and truss models [21-23];

- Rigid body bolt models composed of a flexible bolt shank and a rigid bolt head [24-27];

- Bolt models of the spider type $[28,29]$.

As it is written above, the systemic approach to modeling multi-bolted joints enables modeling each of the subsystems individually using models of varying complexity in order to find the best of them. This applies to particular bolts. Some theoretical studies on the process of pre-tensioning of the asymmetrical multi-bolted joint, consisting of a flange fixed to a rigid support, have been introduced in the previous paper [13]. The bolts were treated as elements with a rigid head in that study. This paper is a continuation of the work just mentioned. It presents the results of modeling the pre-tensioning process for the modified joint model also using the finite element method, but with other models of bolts. The bolts are now regarded as bolt models of the spider type [28].

Modeling and calculations of a linear multi-bolted joint model should be considered in two stages. This paper describes the model in the assembly condition. The model in the operational condition is presented in a separate paper [30].

\section{Model of the joint based on the system approach}

The concept of the modeling method of multi-bolted joints used in this paper is presented in [13]. The joint model is made up of a flexible flange that is connected to a rigid support using $k$ bolts, as shown in Figure 1. The bolts are replaced by bolt models of the spider type [28] with the stiffness coefficient $c_{y i}$ (where

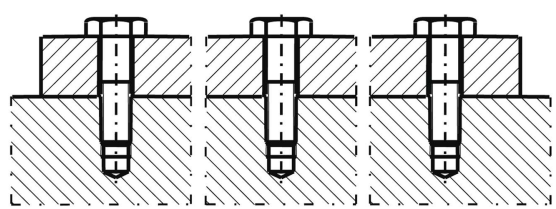

(a)
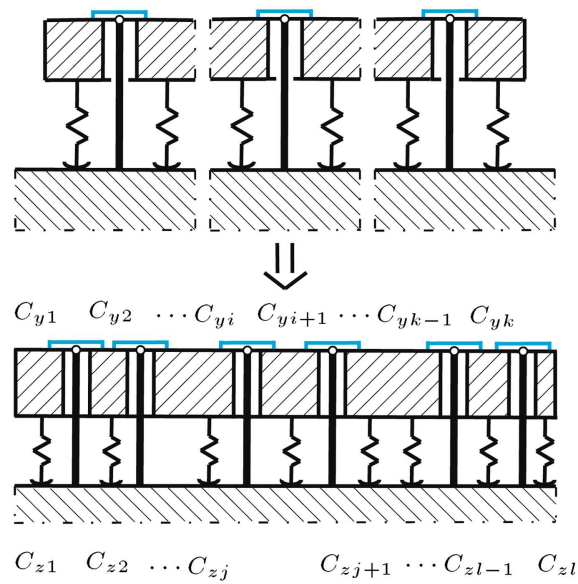

(b)

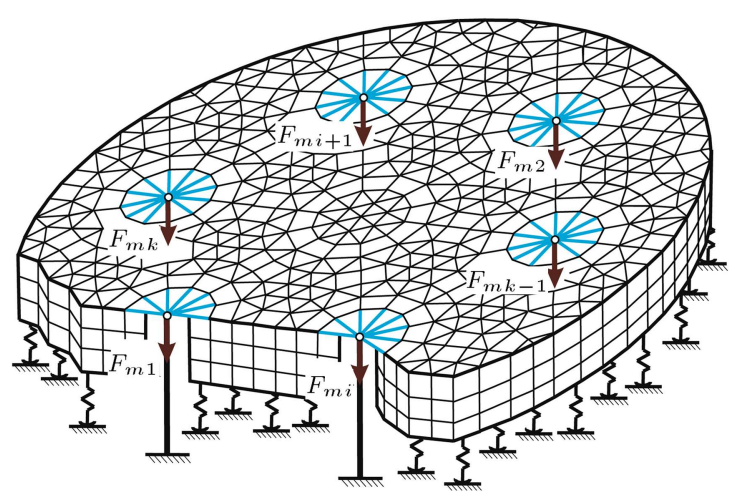

(c)

Figure 1. Model of the joint: (a) Diagram, (b) spring properties of the joint elements, and (c) finite element model.

$i=1,2, \cdots, k)$. The essence of each such bolt element is that their shank is modeled by means of the beam element with a cross-sectional dimension corresponding to the size of the bolt; however, its head is modeled with use of several beams built as a spider connecting the nodes lying in the real bolt in the bolt head area and having a total volume, such as the volume of the real bolt head.

The Winkler elastic foundation model [31] is added between the joined elements as a model of the contact layer. This type of contact layer model can be characterised by $l$ one-sided linear springs with the stiffness coefficient $c_{z j}$ (where $j=1,2, \cdots, l$ ). It is defined by the following function:

$$
R_{m j}=A_{j} \cdot f\left(\delta_{j}\right),
$$

where $R_{m j}$ is the force located in the geometric center 
of the elementary contact area no. $j(\mathrm{~N}), A_{j}$ is the elementary contact area no. $j\left(\mathrm{~mm}^{2}\right)$, and $\delta_{j}$ represents the deformation of the linear spring no. $j(\mu \mathrm{m})$ located in the contact layer.

The contact layer model springs pose a flexible contact model and join the surfaces of the flexible flange and the rigid support. Thus, the surfaces of the joined elements are not in direct contact. They are separated by the contact layer, made up of springs. During the calculation process, the springs that are not loaded in the current step are excluded from the model.

The equilibrium equation of the system shown in Figure 1 can be represented as:

$$
\mathbf{K} \cdot \mathbf{q}=\mathbf{p}
$$

where $\mathbf{K}$ is the stiffness matrix of the multi-bolted system, $\mathbf{q}$ is the displacements vector of the multibolted system, and $\mathbf{p}$ denotes the loads vector of the multi-bolted system.

The following three different subsystems can be identified in the discussed multi-bolted joint:

- Subsystem made up of the bolts, referred to as subsystem B;

- Subsystem associated with the flexible flange referred to as subsystem $\mathbf{F}$;

- Conventional contact layer subsystem referred to as subsystem C.

Then, Eq. (2) can be expressed in the form:

$$
\left[\begin{array}{ccc}
\mathbf{K}_{B B} & \mathbf{K}_{B F} & \mathbf{0} \\
\mathbf{K}_{F B} & \mathbf{K}_{F F} & \mathbf{K}_{F C} \\
\mathbf{0} & \mathbf{K}_{C F} & \mathbf{K}_{C C}
\end{array}\right] \cdot\left[\begin{array}{c}
\mathbf{q}_{B} \\
\mathbf{q}_{F} \\
\mathbf{q}_{C}
\end{array}\right]=\left[\begin{array}{c}
\mathbf{p}_{B} \\
\mathbf{0} \\
\mathbf{0}
\end{array}\right],
$$

where $\mathbf{K}_{B B}, \mathbf{K}_{F F}$, and $\mathbf{K}_{C C}$ are stiffness matrices of subsystems $\mathbf{B}, \mathbf{F}$, and $\mathbf{C} ; \mathbf{K}_{B F}, \mathbf{K}_{F B}, \mathbf{K}_{F C}$, and $\mathbf{K}_{C F}$ are matrices of elastic couplings among subsystems $\mathbf{B}$, $\mathbf{F}$, and $\mathbf{C} ; \mathbf{q}_{B}, \mathbf{q}_{F}$, and $\mathbf{q}_{C}$ are displacements vectors of subsystems $\mathbf{B}, \mathbf{F}$, and $\mathbf{C}$; and $\mathbf{p}_{B}$ represents the loads vector of subsystem $\mathbf{B}$.

Thanks to such a multi-bolted joint model, forces in the bolts can be determined both during and after the assembly of the joint.

The pre-tensioning process is an iterative process, which is composed of $k$ steps, in pursuance of the sum of bolts forming the multi-bolted joint (Figure 2). The process starts from tightening the first bolt. Therefore, the system consists of a flange supported on a linear elastic foundation and is only clamped with a single bolt. In the first step, the system is loaded with the preload of the bolt no. 1, i.e., with the force $F_{m 1}$. As a result of the solution to Eq. (3), the vector of displacements of linear springs $\mathbf{q}_{C}$ :

$$
\mathbf{q}_{C}=\operatorname{col}\left(q_{C 1}, q_{C 2}, \cdots, q_{C j}, \cdots, q_{C l}\right),
$$

is obtained. It contains the initial deformation of linear springs for the next step of the calculation process.

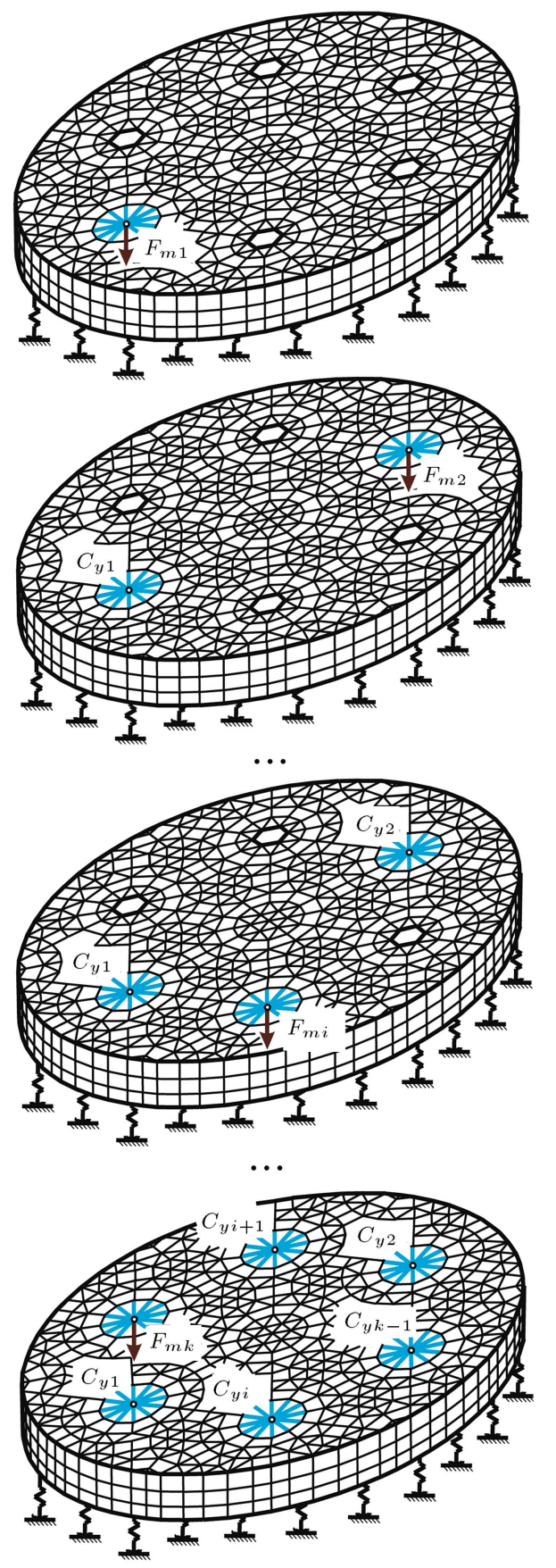

Figure 2. Pre-tensioning process of the multi-bolted joint.

In the following joint tightening steps (when $i=$ $2,3, \cdots, k)$, in the system, the next spider bolt model is activated. This also causes that the stiffness matrix of the bolts subsystem $\mathbf{K}_{B B}$ in Eq. (3) is supplemented by the element that corresponds to the bolt model added in the current calculation step. Besides, it should be noted that in the current step of joint tightening, the stiffness matrix $\mathbf{K}$ is inter alia composed of the following two parts:

- The constant stiffness matrix $\mathbf{K}_{B B}$; 


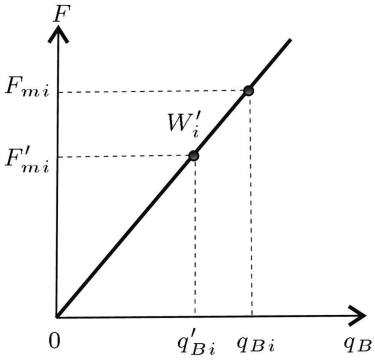

(a)

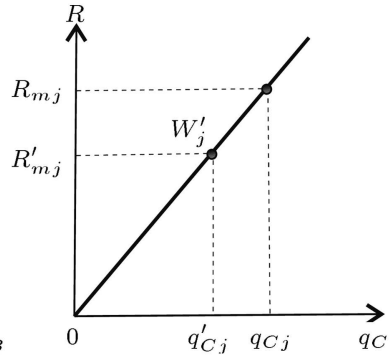

(b)
Figure 3. Determining of the load: (a) For the bolts and (b) for elements of the contact layer [13].

- The variable stiffness matrix $\mathbf{K}_{C C}$.

The final linear springs displacements, $q_{C j}$, in the current step of the joint tightening are determined from the operating points, $W_{j}^{\prime}$, which denote their state of deformation in the previous calculation step (Figure $3(\mathrm{~b}))$. Using $q_{C j}$ identified by the displacements in this method, the forces $R_{m j}$ can be designated from Eq. (1) for $\delta_{j}$ equal to $q_{C j}$. The calculation process is kept running in $k$ iterations to achieve the values of the contact layer forces at which the following condition will be fulfilled:

$$
\left|\frac{R_{m j}^{\prime}-R_{m j}}{R_{m j}}\right| \leq \alpha,
$$

where $\alpha$ denotes the admissible error of the calculation process.

When Eq. (3) is solved, also the displacements vector of bolts $\mathbf{q}_{B}$ :

$$
\mathbf{q}_{B}=\operatorname{col}\left(q_{B 1}, q_{B 2}, \cdots, q_{B i}, \cdots, q_{B k}\right),
$$

is obtained.

The final bolts displacements $q_{B i}$ in the current step of the joint tightening are determined from the operating points, $W_{i}^{\prime}$, which denote their state of deformation in the previous calculation step (Figure 3(a)). Using $q_{B i}$ identified by the displacements in this method, the bolt forces $F_{m i}$ can be computed on the basis of the formula:

$$
F_{m i}=c_{y i} \cdot q_{B i} .
$$

A block diagram of the iterative process of calculating the multi-bolted joint is illustrated in Figure 4.

\section{Results of multi-bolted joint calculations}

In reference to the described method, the calculations for the exemplary asymmetric multi-bolted joint

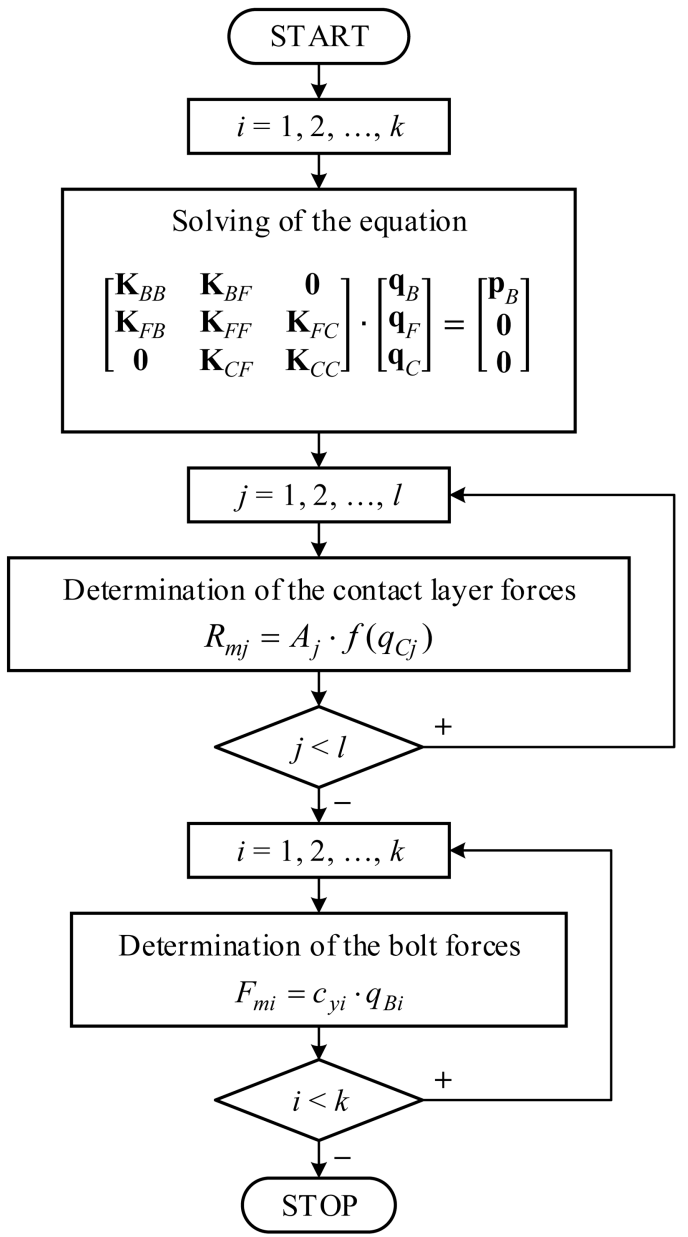

Figure 4. Block diagram of iterative calculations of the multi-bolted joint.

formed by seven M10 bolts were carried out. This joint was tested on a laboratory stand and the test results are described in reference [32]. A simplified FE-model of the joint and the numbering and positioning of the bolts are illustrated in Figure 5(a). Calculations were performed for the flange having a thickness of $20 \mathrm{~mm}$.

The model of the joint has been fastened in the manner, shown in Figure 5, by:

- Receiving degrees of freedom in all directions at the bottom of the conventional contact layer;

- Receiving degrees of freedom in a plane perpendicular to the axis of the bolts in five nodes on the circumference of the flange.

In this case, the bolts preload $F_{m i}$ is $20 \mathrm{kN}$. The sequence of the bolts tightening is given in Table 1 . It is one of the four tightening sequences tested in [32],

Table 1. Tightening sequence of the joint.

\begin{tabular}{llllllll}
\hline Number of the bolt & 1 & 2 & 3 & 4 & 5 & 6 & 7 \\
Sequence of bolt tightening & 1 & 4 & 7 & 3 & 6 & 2 & 5 \\
\hline
\end{tabular}




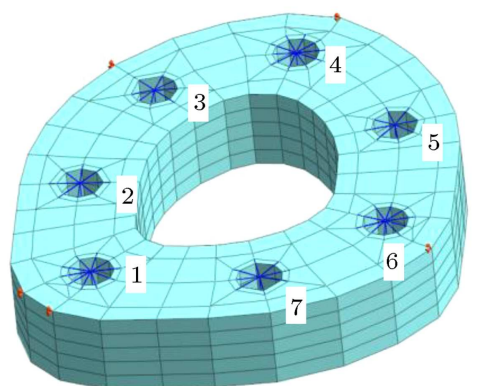

(a)

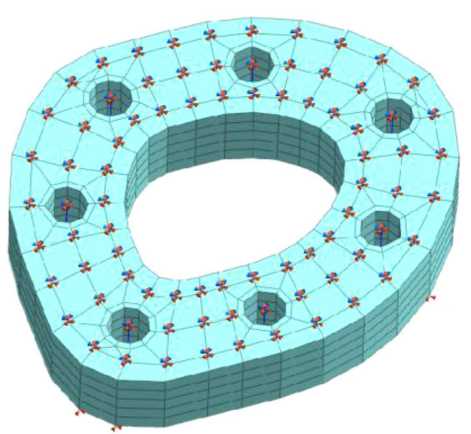

(b)

Figure 5. Adopted multi-bolted joint: (a) FEM-based model and (b) fastening of the model.

for which the smallest scattering of preload values in the bolts at the end of the pre-tensioning process has been achieved. The tightening procedure was performed in one pass. However, it is possible to carry out this procedure in a few passes, for example following the recommendations given in [33]. Linear characteristics of the springs forming the contact layer are specified by the following function defined on the basis of experimental tests [13]:

$$
R_{m j}=A_{j} \cdot\left(26.873 \cdot \delta_{j}\right)
$$

The calculation results are presented in the graphs shown in Figure 6, in which force variations in the bolts during the pre-tensioning process are presented according to the following scheme:

- In line no. 1 - the preload variations in the first pretensioned bolt (no. 1);

- In line no. 2 - the preload variations in the second and the seventh pre-tensioned bolts (marked with numbers 4 and 5);

- In line no. 3 - the preload variations in the third and the sixth pre-tensioned bolts (marked with numbers 7 and 2);

- In the last line - the preload variations in the fourth and the fifth bolts (marked with numbers 3 and 6 ).

The scattering of the final bolts preload values can be seen by reading the preload values in bolts after
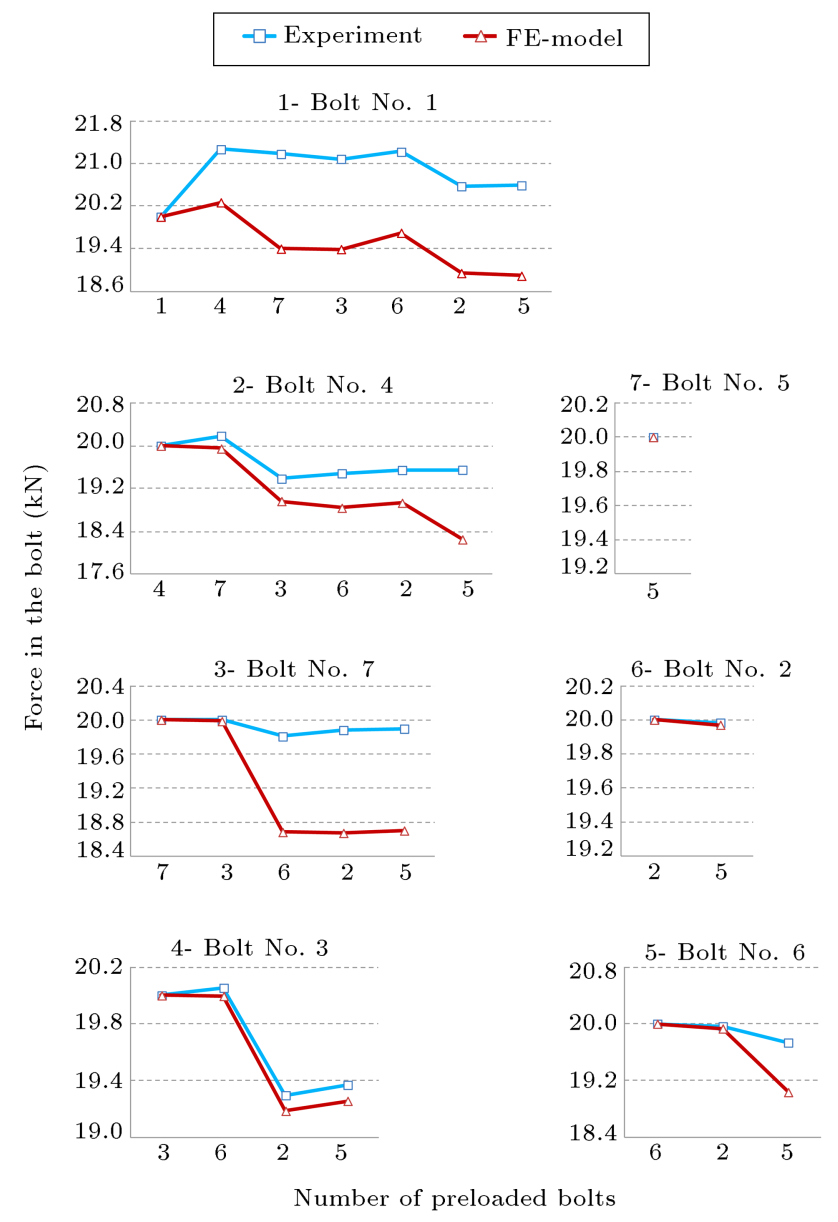

Figure 6. Preload values during the pre-tensioning process.

tightening of the bolt no. 5 on the individual graphs shown in Figure 6.

By observing the obtained results, it can be seen that the bolts preload values are irregularly variable during the entire pre-tensioning process. Adoption of the proposed multi-bolted joint model may cause variability of the bolt preloads during the pre-tensioning process in the range from $-8.7 \%$ to $1.4 \%$ in relation to their initial values.

The calculated values of each bolt preload during and at the end of the pre-tensioning process are compared with their experimental values [32]. The relative evaluation of the final bolts preload values can be carried out using the $Z$ rate:

$$
Z=\left|\frac{F_{m i}^{\mathrm{FEM}}-F_{m i}^{\mathrm{EXP}}}{F_{m i}^{\mathrm{EXP}}}\right| \cdot 100,
$$

where $F_{m i}^{\mathrm{FEM}}$ represents the final preload of the $i$ th bolt following the linear FE-model of the multi-bolted joint and $F_{m i}^{\text {EXP }}$ is the final preload of the $i$ th bolt obtained experimentally [32].

The results summarized in Figure 6 show that adoption of a linear multi-bolted joint model is gen- 
erally associated with the achievement of the preload in bolts reduced relative to the values determined experimentally. A detailed extension of this conclusion can be derived from the $Z$ rate. Based on its values, it can be concluded that the adoption of the proposed multi-bolted joint model may cause a change in the final bolt preloads up to $-8.3 \%$ by comparison with their experimental values [32].

\section{Conclusions}

The performed calculations and analyses lead to the following general conclusions:

1. In the face of the tightening of multi-bolted joints, nonlinear characteristics of the layer at the contact between the joined elements may have an insignificant impact on the final computational values of bolt preloads. Therefore, linear models of the contact layer between the joined elements can be used to calculate and analyse such joints. Then, the task becomes less complex and its solution becomes more efficient and less time consuming;

2. The resulting calculation procedures can be used to optimize the preload of the individual bolts in order to ensure uniform pressure distribution at the interface between elements connected in the multibolted joint;

3. The multi-bolted joint model can be used successfully in the analysis of the preload variance of the connections in accordance with the adopted assumptions of the model. In addition, the scope of application of the calculation method can be extended to the case of joints made from a pair of flexible joined elements. The results of studies on this theme will be published in future papers.

\section{Nomenclature}

$A_{j} \quad$ Elementary contact area no. $j\left(\mathrm{~mm}^{2}\right)$

$c_{y i} \quad$ Stiffness coefficient of the bolt model no. $i(\mathrm{~N} / \mathrm{mm})$

$c_{z j} \quad$ Stiffness coefficient of the linear spring no. $j(\mathrm{~N} / \mathrm{mm})$

$F_{m i} \quad$ Preload of the bolt no. $i(\mathrm{kN})$

K Stiffness matrix of the multi-bolted system

p Loads vector of the multi-bolted system

q Displacements vector of the multibolted system

$R_{m j} \quad$ Force located in the geometric center of the elementary contact area no. $j$ (N)
$Z \quad$ Accuracy rate (\%)

\section{Greek symbols}

$\alpha \quad$ Admissible error of the calculation process

$\delta_{j} \quad$ Deformation of the linear spring no. $j$ located in the contact layer $(\mu \mathrm{m})$

\section{Superscripts}

' Calculation step with the number $i-1$

\section{Subscripts}

$B \quad$ Set of bolts

C Linear contact layer

$F \quad$ Flange

$i \quad$ Sequence number of the bolt (where $i=1,2, \cdots, k)$

$j \quad$ Sequence number of the linear spring (where $j=1,2, \cdots, l$ )

\section{Acronyms}

EXP Experiment

FEM Finite Element Method

\section{References}

1. Abid, M. "Stress variation in the flange of a gasketed flange pipe joint during bolt up and operating conditions", Sci. Iran., 13(3), pp. 303-309 (2006).

2. Ascione, F. "A preliminary numerical and experimental investigation on the shear stress distribution on multi-row bolted FRP joints", Mech. Res. Commun., 37(2), pp. 164-168 (2010).

3. Tsiampousi, A., Yu, J., Standing, J., Vollum, R., and Potts, D. "Behaviour of bolted cast iron joints", Tunn. Undergr. Sp. Tech., 68, pp. 113-129 (2017).

4. Palásti-Kovács, B., Sipos, S., and Bíró, S. "The mysteries of the surface. First part: The characteristic features of the microgeometry of the machined surface", Acta Polytech. Hung., 11(5), pp. 5-24 (2014).

5. Wang, L., Liu, H., Zhang, J., and Zhao, W. "Analysis and modeling for flexible joint interfaces under micro and macro scale", Precision Engineering, 37(4), pp. 817-824 (2013).

6. Abdo, J. "Modeling of frictional contact parameters of mechanical systems", International Journal of Applied Mechanics and Engineering, 11(3), pp. 449-465 (2006).

7. Grudziński, K. and Kostek, R. "An analysis of nonlinear normal contact microvibrations excited by a harmonic force", Nonlinear Dynam., 50(4), pp. 809815 (2007).

8. Kostek, R. "An analysis of the primary and superharmonic contact resonances - Part 2", J. Theor. Appl. Mech., 51(3), pp. 687-696 (2013). 
9. Misra, A. and Huang, S. "Effect of loading induced anisotropy on the shear behavior of rough interfaces", Tribol. Int., 44(5), pp. 627-634 (2011).

10. Abid, M., Khan, A., Nash, D.H., Hussain, M., and Wajid, H.A. "Simulation of optimized bolt tightening strategies for gasketed flanged pipe joints", Procedia Engineer., 130, pp. 204-213 (2015).

11. Abid, M. and Nash, D.H. "Structural strength: Gasketed vs non-gasketet flange joint under bolt up and operating condition", Int. J. Solids Struct., 43(14-15), pp. 4616-4629 (2006).

12. Grzejda, R. "Modelling nonlinear multi-bolted connections: A case of the assembly condition", 15th Int. Sci. Conf. Engrg for Rural Dev., Jelgava, Latvia, pp. 329335 (2016).

13. Grzejda, R. "Non-linearity of the contact layer between elements joined in a multi-bolted connection and the preload of the bolts", Combustion Engines, 55(2), pp. 3-8 (2016).

14. Błachowski, B. and Gutkowski, W. "Effect of damaged circular flange-bolted connections on behaviour of tall towers, modelled by multilevel substructuring", Eng. Struct., 111, pp. 93-103 (2016).

15. Hu, F., Shi, G., Bai, Y., and Shi, Y. "Seismic performance of prefabricated steel beam-to-column connections", J. Constr. Steel Res., 102, pp. 204-216 (2014).

16. Kalogeropoulos, A., Drosopoulos, G.A., and Stavroulakis, G.E. "Thermal-stress analysis of a three-dimensional end-plate steel joint", Constr. Build. Mater., 29, pp. 619-626 (2012).

17. Keikha, H. and Mofid, M. "On the assessment of a new steel bolted flush end-plate beam splice connection", Sci. Iran. Trans. A, 24(4), pp. 1735-1750 (2017).

18. Esfahanian, A., Mohamadi-Shooreh, M.R., and Mofid, M. "Assessment of the semi-rigid double-angle steel connections and parametric analyses on their initial stiffness using FEM", Sci. Iran., Trans. A, 22(6), pp. 2033-2045 (2015).

19. Simões, R., Jordão, S., Diogo, J., and Fernandes, J. "Development and design of a concealed splice joint configuration between tubular sections", Eng. Struct., 137, pp. 181-193 (2017).

20. Pavlović, M., Marković, Z., Veljković, M. and Buđevac, D. "Bolted shear connectors vs. headed studs behaviour in push-out tests", J. Constr. Steel Res., 88, pp. 134-149 (2013).

21. Li, Z., Soga, K., Wang, F., Wright, P., and Tsuno, K. "Behaviour of cast-iron tunnel segmental joint from the 3D FE analyses and development of a new bolt-spring model", Tunn. Undergr. Sp. Tech., 41, pp. 176-192 (2014).
22. Luan, Y., Guan, Z.-Q., Cheng, G.-D., and Liu, S. "A simplified nonlinear dynamic model for the analysis of pipe structures with bolted flange joints", J. Sound Vib., 331(2), pp. 325-344 (2012).

23. Smolnicki, T., Derlukiewicz, D., and Stańco, M. "Evaluation of load distribution in the superstructure rotation joint of single-bucket caterpillar excavators", Automat. Constr., 17(3), pp. 218-223 (2008).

24. Aguirrebeitia, J., Abasolo, M., Avilés, R., and de Bustos, I.F. "General static load-carrying capacity for the design and selection of four contact point slewing bearings: Finite element calculations and theoretical model validation", Finite Elem. Anal. Des., 55, pp. 23-30 (2012).

25. Hammami, C., Balmes, E., and Guskov, M. "Numerical design and test on an assembled structure of a bolted joint with viscoelastic damping", Mech. Syst. Signal Pr., 70-71, pp. 714-724 (2016).

26. Palenica, P., Powałka, B., and Grzejda, R. "Assessment of modal parameters of a building structure model", Springer Proceedings in Mathematics \& Statistics, 181, pp. 319-325 (2016).

27. Prinz, G.S., Nussbaumer, A., Borges, L., and Khadka, S. "Experimental testing and simulation of bolted beam-column connections having thick extended endplates and multiple bolts per row", Eng. Struct., 59, pp. 434-447 (2014).

28. Grzejda, R. "New method of modelling nonlinear multi-bolted systems", In Advances in Mechanics: Theoretical, Computational and Interdisciplinary Issues, M. Kleiber, T. Burczyński, K. Wilde, J. Górski, K. Winkelmann, Ł. Smakosz, Eds., pp. 213-216, CRC Press, Leiden, Netherlands (2016).

29. Kim, J., Yoon, J.-Ch., and Kang, B.-S. "Finite element analysis and modeling of structure with bolted joints", Appl. Math. Model., 31(5), pp. 895-911 (2007).

30. Grzejda, R. "Impact of nonlinearity of the contact layer between elements joined in a preloaded bolted flange joint on operational forces in the bolts", $\mathrm{Me}$ chanics and Mechanical Engineering, 21(3), pp. 541548 (2017).

31. Ozgan, K. and Daloglu, A.T. "Dynamic analysis of thick plates on elastic foundations using Winkler foundation model", Sci. Iran., Trans. A, 21(1), pp. 11-18 (2014).

32. Grzejda, R., Witek, A., and Konowalski, K. "Experimental investigations of an asymmetrical bolted connection loaded by an eccentric force" [Doświadczalne badania niesymetrycznego połączenia wielośrubowego obciążonego mimośrodowo], Przegląd Mechaniczny, 71(1), pp. 21-27 (2012).

33. Kumakura, S. and Saito, K. "Tightening sequence for bolted flange joint assembly", 2003 ASME Pressure Vessels and Piping Conference, Analysis of Bolted Joints, Cleveland, USA, pp. 9-16 (2003). 


\section{Biography}

Rafal Grzejda received an MSc degree in Mechanical Engineering from Szczecin University of Technology, Poland, in 2000, and a $\mathrm{PhD}$ degree in the same subject from West Pomeranian University of Tech- nology, Szczecin, Poland, in 2009. He is currently Head of Division of Machine Design Fundamentals at West Pomeranian University of Technology, Szczecin, Poland. His main research interests include computational mechanics, finite element method, and vibration and control analysis. 